\title{
Varicella zoster-associated gastric ulcers, hepatitis and pancreatitis in an immunocompromised patient
}

A 62-year-old man presented with severe, continuous abdominal pain to a general hospital. His previous medical history revealed autologous stem cell transplantation for multiple myeloma 3 months before admission. This was complicated by bronchiolitis obliterans organizing pneumonia (BOOP) for which treatment was instituted with $25 \mathrm{mg}$ prednisone per day. An abdominal computed tomography (CT) scan showed evidence of acute pancreatitis and despite appropriate treatment intense abdominal pain persisted. During the following days he developed a skin rash, which was interpreted as druginduced, and a generalized seizure. After 7 days he was referred to our hospital. Physical examination revealed an ill man in great pain. On clinical examination he had a maculovesicular rash on the face, trunk, and abdomen ( $\bullet$ Fig. 1). Laboratory investigation showed elevated serum aspartate aminotransferase of $1038 \mathrm{U} / \mathrm{l}$ (normal 0-36U/1), alanine aminotransferase $848 \mathrm{U} / \mathrm{l}$ (normal 0 - $40 \mathrm{U} / \mathrm{l}$ ), amylase 158 U/l (normal 0 - 99 U/1), C-reactive protein $57 \mathrm{mg} / \mathrm{l}$ (normal $0-9 \mathrm{mg} / \mathrm{l}$ ), and leukocyte count $3.2 \times 10^{9} / \mathrm{L}$ (normal, 3.5$10.0 \times 10^{9} / \mathrm{L}$ ). A chest X-ray showed diffuse infiltrative pulmonary abnormalities. Upper gastrointestinal endoscopy revealed multiple well-demarcated superficial erosions with a white patchy surface in the esophagus ( Fig. 2). In the fundus, corpus, and antrum of the stomach, multiple ulcers with central necrosis were present, ranging from $5 \mathrm{~mm}$ to $10 \mathrm{~mm}$ in diameter (৫ Fig. 3). The abdominal pain, skin rash, and the multiple ulcerations in the esophagus and stomach raised clinical suspicion of varicella zoster virus (VZV) infection. Polymerase chain reaction (PCR) revealed VZV genome in serum, as well as in skin and gastric biopsies.

VZV is an unsuspected cause of severe acute abdominal pain and patients may present with hepatitis, pancreatitis, and gastroesophageal mucositis. Moreover, VZV infection is the most common viral disease after bone marrow transplantation, occurring in $17-50 \%$ of patients, with a median interval of 3-6 months $[1,2]$. In the majority of cases, cutaneous manifestations precede those of abdomi- nal organ dissemination, making early diagnosis more likely [2]. Timely diagnosis and prompt treatment may diminish mortality, which ranges from $9 \%$ to 55\% [1 3]. In most cases, latent VZV is reactivated from the dorsal root ganglia, which share the afferent sympathetic fibers that supply the liver, pancreas, gastrointestinal mucosa, and lungs [3]. Since posterior sensory nerve roots contain fibers from both skin and abdominal viscera, these organs are potential candidates to be affected [3]. In our patient, all of these organs were affected and after treatment with intravenous aciclovir $10 \mathrm{mg} / \mathrm{kg} / 8 \mathrm{~h}$, the abdominal pain as well as the cutaneous and pulmonary abnormalities disappeared and serum amylase and transaminase levels normalized.

In conclusion, the combination of multiple gastric ulcers, pancreatitis, hepatitis, and a skin rash should raise the possibility of disseminated VZV infection, especially following bone marrow transplantation.

Endoscopy_UCTN_Code_CCL_1AB_2AD_3AC

Competing interests: None

R. G. Remmerswaal, A. C. de Vries, D. Ramsoekh, H. R. van Buuren

Department of Gastroenterology and Hepatology, Erasmus University Medical Center, Rotterdam, the Netherlands

\section{References}

1 Takatoku M, Muroi K, Kawano-Yamamoto C et al. Involvement of the esophagus and stomach as a first manifestation of varicella zoster virus infection after allogeneic bone marrow transplantation. Intern Med 2004; 43: $861-864$

2 Rivera-Vaquerizo PA, Gomez-Garrido J, Vicente-Gutierrez $M$ et al. Varicella zoster gastritis 3 years after bone marrow transplantation for treatment of acute leukemia. Gastrointest Endosc 2001; 53: 809-810

3 Stratman E. Visceral zoster as the presenting feature of disseminated herpes zoster. J Am Acad Dermatol 2002; 46: 771 - 774

\section{Bibliography}

DOI 10.1055/s-0030-1256934

Endoscopy 2012; 44: E140

(c) Georg Thieme Verlag KG Stuttgart · New York .

ISSN 0013-726X

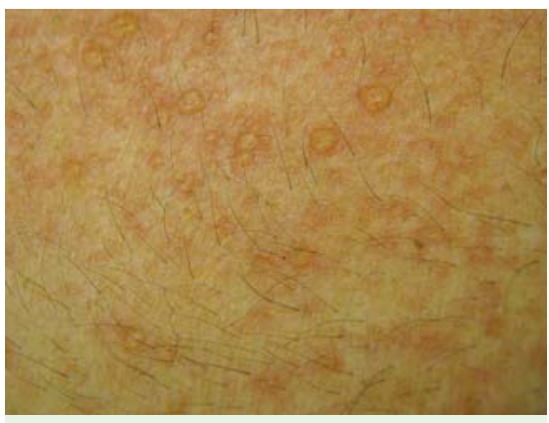

Fig. 1 Maculovesicular skin rash on the trunk.

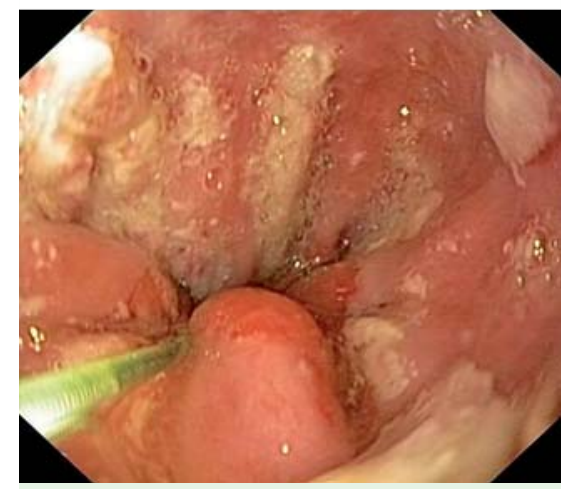

Fig. 2 Multiple well-demarcated superficial erosions with a white patchy surface in the distal esophagus.

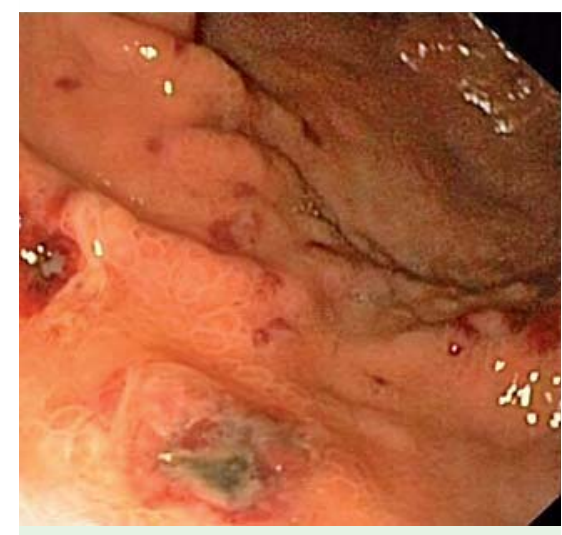

Fig. 3 Ulcers with central necrosis along the greater curvature of the corpus of the stomach.

Corresponding author

\section{A. C. de Vries}

Department of Gastroenterology and Hepatology Erasmus University Medical Center

Rotterdam

The Netherlands

Fax: +31-10-7034682

a.c.devries@erasmusmc.nl 